\title{
Conserved Linkage between the Puffer Fish (Fugu rubripes) and Human Genes for Platelet-derived Growth Factor Receptor and Macrophage Colony-stimulating Factor Receptor
}

\author{
Gee-Fung How, ${ }^{1}$ Byrappa Venkatesh, ${ }^{1,3}$ and Sydney Brenner ${ }^{1,2}$ \\ ${ }^{1}$ Institute of Molecular and Cell Biology, National University of Singapore, Singapore 119260; \\ ${ }^{2}$ Department of Medicine, University of Cambridge Clinical School, Addenbrooke's Hospital, \\ Cambridge CB2 2QQ, UK
}

\begin{abstract}
We have cloned and sequenced the teleost homologs of the human genes encoding platelet-derived growth factor receptor- $\beta$ (PDGFR $\beta$ ) and macrophage colony-stimulating factor 1 receptor (CSFIR) from the puffer fish Fugu rubripes. The Fugu PDGFR $\beta$ and CSFIR genes each consist of 21 coding exons similar to the human CSFIR gene, but are considerably smaller than their human counterparts because of the smaller introns. Furthermore, the two Fugu genes are linked tandemly in a head-to-tail array similar to their human homologs with $2.2 \mathrm{~kb}$ of intergenic sequence. Amino acid sequences of the Fugu and human PDGFR $\beta$ and CSFIR genes show an overall homology of $45 \%$ and $39 \%$, respectively, with the kinase domains showing a much higher degree of conservation. Dot-matrix analysis revealed several short stretches of conserved sequences in the 3 ' untranslated regions of the PDGFR $\beta$ genes and the adjacent promoter regions of the CSFIR genes. These conserved sequences may have a role in the regulation of expression of either or both of these closely linked genes.
\end{abstract}

[The sequence data described in this paper have been submitted to GenBank under accession no. U63926.]

The Japanese puffer fish Fugu rubripes has a small genome of $390 \mathrm{Mb}$ which is $\sim 8$ times smaller than the mammalian genomes (Brenner et al. 1993). Because teleosts have a body plan similar to that of mammals and possess most of their complex physiological functions, it is not surprising that the Fugu genome has a gene repertoire comparable to that of mammals (Brenner et al. 1993). This implies that the gene density in the Fugu genome is higher than in mammalian genomes. The compact genome of Fugu with small introns and a low abundance of repetitive elements (Brenner et al. 1993; Baxendale et al. 1995; Elgar et al. 1995; Mason et al. 1995; Brenner and Corrochano 1996; Maheshwar et al. 1996; Venkatesh et al. 1996) is an efficient model vertebrate genome for comparative genome analysis. Although teleosts diverged $\sim 400$ million years ago

${ }^{3}$ Corresponding author.

E-MAIL mcbbv@nus.sg; FAX 65-779-1117. from the lineage that gave rise to mammals, the gene order on short stretches of chromosomes might be conserved between fishes and mammals. Conserved linkage of genes between the compact genome of Fugu and the expanded human genome would be an advantage in using Fugu genomic sequence for positional cloning of human genes. To assess the extent of conservation of linkage between the Fugu and human genes, we have been sequencing and analyzing the order of $F u g u$ homologs of human genes that are known to be linked closely in the human genome.

Receptors for the human platelet-derived growth factor- $\beta$ (PDGFR $\beta$ ) and macrophage colony-stimulating factor 1 (CSF1R) belong to the same subfamily of receptor tyrosine kinases (Yarden and Ullrich 1988). Members of this family have an extracellular ligand binding domain, a single transmembrane domain, and an intracellular tyrosine kinase domain that is interrupted 
by a hydrophilic spacer consisting of $60-140$ amino acids known as the kinase-insert (KI) domain. Among all the known kinase receptors, PDGFR $\beta$ and CSF1R most closely resemble each other in their amino-acid sequences. Human genes for these receptors have been localized to the long arm of human chromosome 5 and are found to be linked physically in a head-to-tail array, with $<500 \mathrm{bp}$ between the polyadenylation signal of the PDGFR $\beta$ gene and the transcription start point of the CSF1R gene (Roberts et al. 1988). Mouse homologs of these genes are also linked in a similar way (Eccles 1991). The human CSF1R gene comprises 21 coding exons spread across $33 \mathrm{~kb}$ and a short $5^{\prime}$ untranslated exon separated from the first coding exon by a $26-\mathrm{kb}$ intron, and codes for a protein of 972 amino acids (Hampe et al. 1989). The human PDGFR $\beta$ gene codes for a 1106-amino-acid protein (Claesson-Welsh et al. 1988). Although this gene is estimated to span $\sim 55 \mathrm{~kb}$ of genomic DNA, it has been sequenced only at the cDNA level. The human PDGFR $\beta$ and CSF1R genes show a nonoverlapping pattern of expression in different cell types. PDGFR $\beta$ is expressed mainly in mesenchymal cells, whereas CSF1R is expressed in blood cells of mononuclear phagocyte lineage and in placental trophoblasts. The promoter sequences that regulate the cell-type-specific pattern of expression of these genes are yet to be identified. In view of the close proximity of the two genes, it has been proposed that the promoter sequence of the CSF1R gene may be located within the genomic sequence of the PDGFR $\beta$ gene (Roberts et al. 1988). We have now determined the nucleotide sequences of the Fugu homologs of the hu-
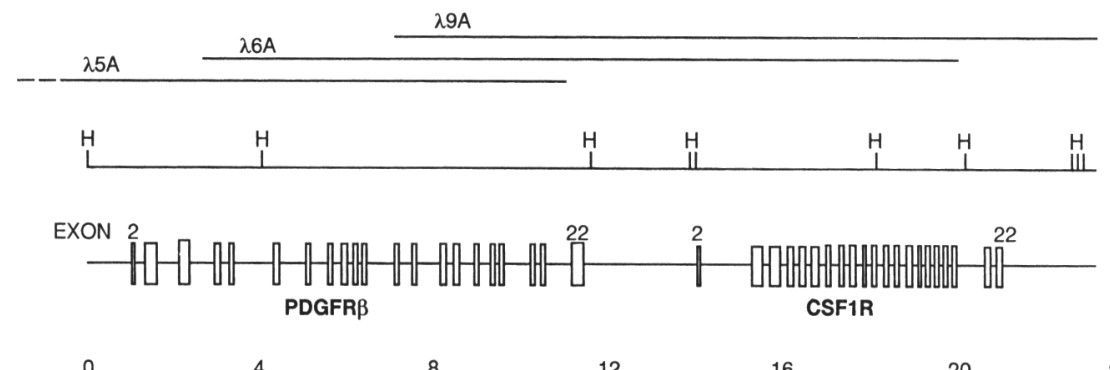

$\begin{array}{lllllll}0 & 4 & 8 & 12 & 16 & 20 & 24 \mathrm{~kb}\end{array}$

Figure 1 Genomic organization of the Fugu PDGFR $\beta$ and CSF1R genes. The complete sequence of the coding exons (corresponding to exons 2 to 22 of the human homologs) of the two genes were obtained from three overlapping $\lambda$ clones $(\lambda 5, \lambda 6$, and $\lambda 9)$ isolated from a Fugu testis genomic library. Sequences of the untranslated exon 1 were not demarcated as the transcription initiation sites were not mapped in this study. Restriction sites of only Hindlll are shown. man PDGFR $\beta$ and CSF1R genes and demonstrate that the two genes are linked closely in the Fugu genome similar to their human counterparts.

\section{RESULTS AND DISCUSSION}

Seven positive recombinant phages that hybridized to the Fugu PDGFR $\beta$ probe were digested with BamHI, EcoRI, HindIII, SacI, XbaI, or XhoI, Southern blotted, and reprobed with the Fugu PDGFR $\beta$ probe. One of the phages, $\lambda 6$, which hybridized strongly to the probe, was selected for subcloning and sequencing. The complete nucleotide sequence of the insert was determined and assembled to generate a $17-\mathrm{kb}$ contig. A homology search of the contig showed that it conlapped with the $5^{\prime}$ end and $3^{\prime}$ end of $\lambda 6$, respectively, were isolated from the Fugu genomic library. The nucleotide sequences of the remaining exons of the PDGFR $\beta$ and CSF1R genes, and the 3 ' untranslated region of CSF1R, were obtained from the subclones of these two phages. A contiguous sequence of $23.2 \mathrm{~kb}$ (GenBank accession no. U63926) that includes all the coding exons of the PDGFR $\beta$ and CSF1R genes was assembled from these sequences (Fig. 1). The sequences for the PDGFR $\beta$ and CSF1R genes are located on the same strand of DNA and are linked tandemly in a head-to-tail array similar to their human homologs (Roberts et al. 1988). The putative polyadenylation signals of the Fugu PDGFR $\beta$ (AATAAA) and CSF1R (ATTAAA) genes are located 148 and 1300 bases from their respective termination codons. The first codon of the CSF1R gene is separated from the polyadenylation signal of the PDGFR $\beta$ gene by $2.2 \mathrm{~kb}$. This distance is $\sim 27 \mathrm{~kb}$ in man, but includes a large intron of $26 \mathrm{~kb}$ in the 5 ' untranslated region of CSF1R gene.

The genomic structures of the Fugu PDGFR $\beta$ and CSF1R genes were deduced by comparison with the amino acid sequences of their 
CONSERVED LINKAGE BETWEEN FUGU PDGFR AND CSFIR

mammalian homologs, the exon-intron structure of the human CSF1R gene, and consensus splice junction sequences. Both Fugu genes consist of 21 coding exons each and therefore have a genomic structure similar to that of the human CSF1R gene. In addition to coding exons, the human CSF1R gene has a $5^{\prime}$ untranslated exon which is separated from the first coding exon by a $26-\mathrm{kb}$ intron (Hampe et al. 1989). Because the transcription initiation sites of the Fugu genes were not mapped in this study, it is not known whether the Fugu genes have the additional untranslated exon. However, it is reasonable to assume that the transcription initiation site of the Fugu CSF1R gene lies within the $2.2-\mathrm{kb}$ intergenic region, and if there is any intron in the $5^{\prime}$ untranslated region, it would be $<2.2 \mathrm{~kb}$. Although the Fugu genes have a genomic complexity similar to that of their human homologs, the overall sizes of Fugu genes are smaller than the human genes. The size of the Fugu CSF1R gene is $<10.6 \mathrm{~kb}$ from the translation initiation site to the polyadenylation signal as opposed to $59 \mathrm{~kb}$ for the human CSF1R gene (Hampe et al. 1989). Likewise, the coding exons of the Fugu PDGFR $\beta$ gene span $10.5 \mathrm{~kb}$ (from first codon to polyadenylation signal) compared with the estimated size of $29 \mathrm{~kb}$ for the human PDGFR $\beta$ gene (Roberts et al. 1988). Therefore the Fugu genes are considerably smaller than the human genes, and the decrease in size is attributable to their smaller introns. The introns of the Fugu PDGFR $\beta$ gene range in size from 96 to 959 bp and those of the CSF1R gene range from 60 to 1194 bp (Table 1). The majority of the Fugu CSF1R introns are much smaller than their human counterparts with the maximum compression occurring in the first intronic sequence (Table 1). This intron is $-26 \mathrm{~kb}$ in the human gene and $<2.3 \mathrm{~kb}$ in the Fugu gene. We now have several examples of "compact" Fugu genes, such as the genes for Huntington's disease (Baxendale et al. 1995), glucose-6phosphate dehydrogenase (Mason et al. 1995), tuberous sclerosis 2 (Maheshwar et al. 1996), and histidyl-tRNA-synthetase (Brenner and Corrochano 1996), which are 2.5-8 times smaller than their mammalian homologs. In all of these Fugu genes, the compaction has occurred mainly in the intronic sequences, with dramatic reductions observed in unusually large introns of mammalian genes, such as the first intron of the human CSF1R gene and the second intron of the Huntington's disease gene $(12.2 \mathrm{~kb}$ reduced to $137 \mathrm{bp}$ in the $F u g u)$. Therefore, it is not surprising that human genes that lack "large" introns have undergone little or no reduction in size in the Fugu. For in-

\begin{tabular}{|c|c|c|}
\hline Intron no. & PDGFRß & CSF1R (Human) \\
\hline 1 & - & $<2200(26000)$ \\
\hline 2 & 313 & 1194 (5349) \\
\hline 3 & 582 & $103(430)$ \\
\hline 4 & 428 & $73(1803)$ \\
\hline 5 & 225 & $79(676)$ \\
\hline 6 & 959 & $83(3780)$ \\
\hline 7 & 407 & $253(2730)$ \\
\hline 8 & 420 & 319 (153) \\
\hline 9 & 114 & $93(118)$ \\
\hline 10 & 142 & $215(1542)$ \\
\hline 11 & 102 & $92(6395)$ \\
\hline 12 & 641 & $140(127)$ \\
\hline 13 & 263 & $153(517)$ \\
\hline 14 & 550 & 133 (999) \\
\hline 15 & 100 & $90(2107)$ \\
\hline 16 & 393 & 79 (119) \\
\hline 17 & 193 & $80(945)$ \\
\hline 18 & 96 & $82(81)$ \\
\hline 19 & 593 & $60(690)$ \\
\hline 20 & 104 & $704(806)$ \\
\hline 21 & 548 & $100(97)$ \\
\hline \multicolumn{3}{|c|}{$\begin{array}{l}\text { Intron } 1 \text { found in the } 5^{\prime} \text { untranslated region of the human } \\
\text { CSF1R gene was not mapped in the Fugu. Sizes of the } \\
\text { human CSF1R introns (Hampe et al. 1989) are given in } \\
\text { parentheses. Introns of the human PDCFR } 3 \text { gene have not } \\
\text { yet been sequenced. }\end{array}$} \\
\hline
\end{tabular}

stance, the genes for $\beta$-cytoplasmic actin, $\alpha$-cardiac actin (Venkatesh et al. 1996), and growth hormone (B. Venkatesh and S. Brenner, unpubl.) are of similar sizes in Fugu and humans.

The coding sequences of the Fugu PDGFR $\beta$ and CSF1R genes predict protein sequences with 1048 and 975 residues, respectively (Figs. 2 and $3)$. The two proteins exhibit similar primary structures comprising an extracellular ligandbinding domain and an intracellular kinase domain separated by a single transmembrane domain rich in hydrophobic amino acid residues. The extracellular ligand-binding domains contain the characteristic pattern of 10 cysteine residues that is found in the extracellular domains of the immunoglobulins. As with their mammalian homologs, the kinase domains of the Fugu PDGFR $\beta$ and CSF1R sequences are interrupted by a kinase insert domain comprising 103 and 70 amino acids, respectively (Figs. 2 and 3). The two Fugu protein sequences exhibit an overall similarity of $32 \%$, with the first half of the kinase do- 


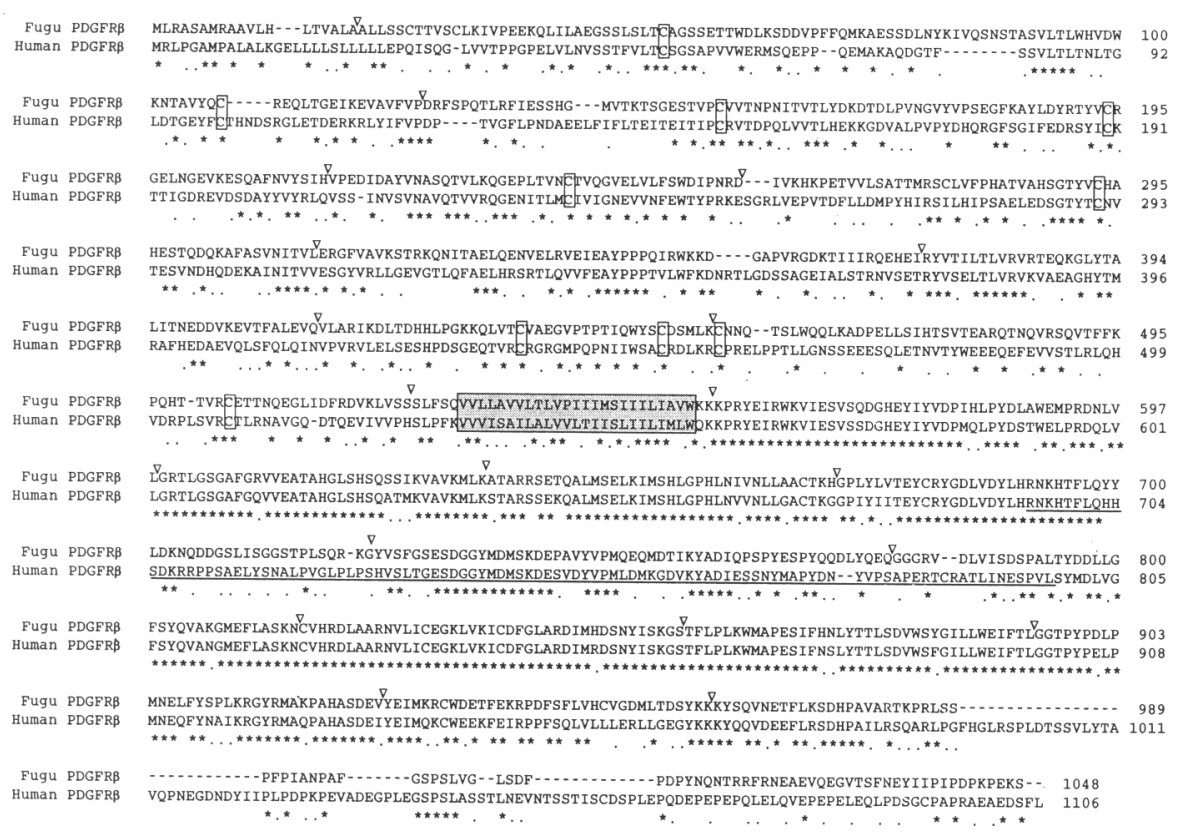

Figure 2 Clustal $W$ alignment of the deduced amino acid sequences of Fugu and human (Claesson-Welsh et al. 1988) PDGFR $\beta$ genes. Asterisks indicate identical residues and periods indicate conservative substitutions. The conserved cysteine residues in the extracellular ligand-binding domains are boxed. Transmembrane domain is boxed and shaded. Kinase-insert domain that splits the intracellular kinase domain is underlined. Arrowheads indicate intron positions in the Fugu gene.

main showing a much higher degree of similarity of $63 \%$.

A comparison of the deduced amino acid sequences of the Fugu PDGFR $\beta$ and CSF1R genes with their human counterparts (Figs. 2 and 3 ) shows that most of the significant residues, particularly in the catalytic domain, are conserved. The amino-acid sequences of the Fugu PDGFR $\beta$ and CSF1R show an overall homology of $45 \%$ and $39 \%$, respectively, with their human homologs. The homology is particularly high in the kinase domains that have a crucial role in intracellular signal transduction through kinase activity. The glycine rich motif Gly-X-Gly-X-X-Gly (residues 603-608 in PDGFR $\beta$ and residues 591596 in CSF1R) associated with nucleotide binding, and the predicted ATP-binding site (Lys 630 in PDGFR $\beta$ and Lys 619 in CSF1R) are conserved in both Fugu genes. The consensus tyrosine residue present in the catalytic domain of all tyrosine kinases is located at residue 852 in the Fugu PDGFR $\beta$ (Tyr-857 in human) and at residue 813 in the Fugu CSF1R (Tyr-809 in human). Although the kinase-insert domains of both Fugu receptors exhibit a lower degree of homology compared with the flanking splitkinase domains, most of the tyrosine residues of this domain that are implicated in autophosphorylation and binding of the receptors to cellular substrates in mammals are conserved in Fugu. In the murine CSF1R receptor, three autophosphorylation sites, Tyr-697, Tyr-706, and Tyr-721, corresponding to the $\mathrm{Fugu}$ CSF1R Tyr-700, Tyr-709, and Tyr-724, have been identified in the kinase insert domain and mutation of either Tyr-697 or Tyr721 has been shown to abrogate signal transduction when expressed in Rat-2 fibroblasts (van der Geer and Hunter 1993). Tyr-721 is crucial for the binding of the receptor to PI 3 '-kinase in mammalian cells (Reedijk et al. 1992) and Tyr-697 in murine CSF1R is the binding site for GRB2 (van der Geer and Hunter 1993). Comparison of protein sequences from distantly related species such as teleosts and mammals provides useful clues to identify important functional domains of the proteins. Protein sequence comparisons of Fugu and human PDGFR $\beta$ and CSF1R have revealed several conserved residues in the extracellular and intracelluar domains whose functions are not known at present. Functional analysis of these residues may throw light on the molecular mechanisms of signal transduction by these tyrosine kinase receptors.

Two separate transcription initiation sites have been reported for the human CSF1R gene transcripts expressed in monocytes and placental cells (Visader and Verma 1989). The transcripts in the monocytes originate within the 26-kb intron in the $5^{\prime}$ untranslated region, whereas those in the placental cells initiate upstream of the noncoding exon located $5^{\prime}$ to the $26-\mathrm{kb}$ intron. Transfection studies in human cell lines and mouse fibroblasts have shown that the promoter elements driving the cell-type specific transcription are located within $1 \mathrm{~kb}$ upstream of the independent transcription start sites (Roberts et al. 


\section{CONSERVED LINKAGE BETWEEN FUGU PDGFR AND CSFIR}

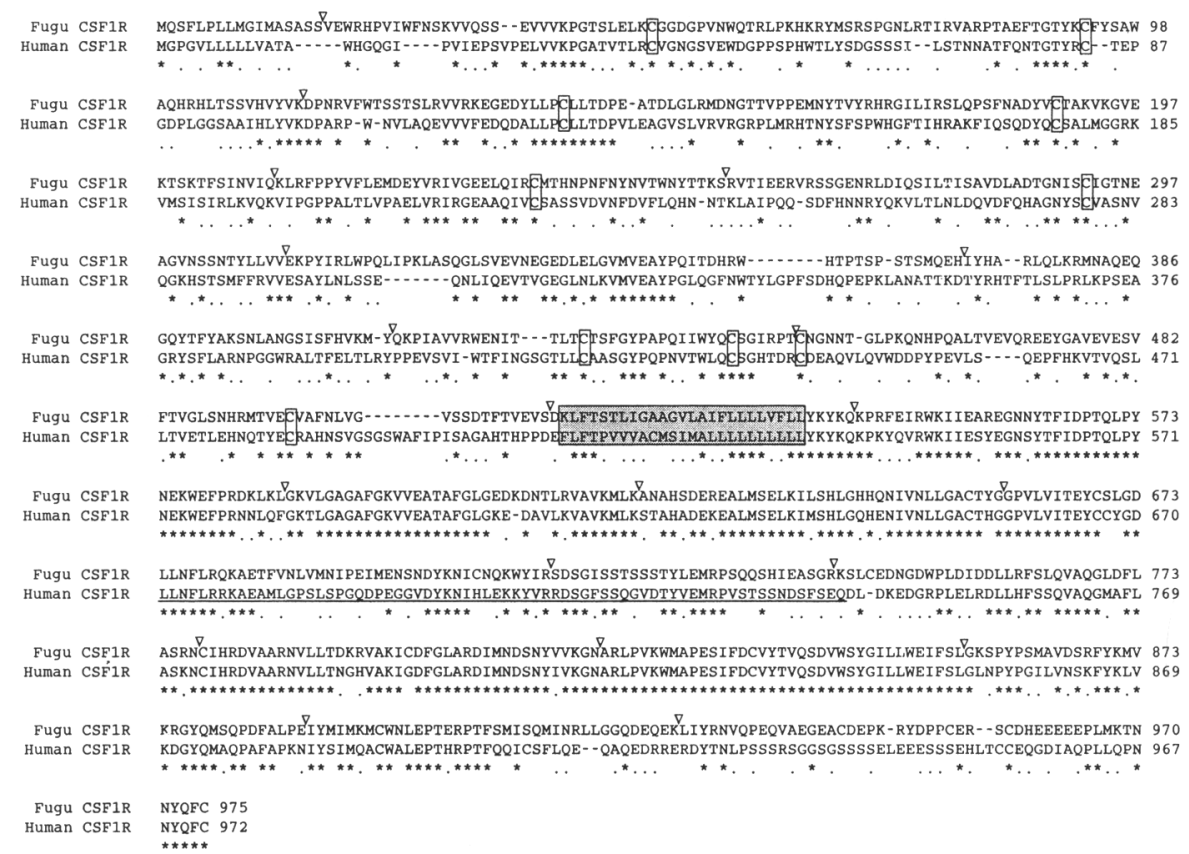

Figure 3 Clustal $\mathrm{W}$ alignment of the deduced amino acid sequences of Fugu and human (Coussens et al. 1986) CSF1R genes. Asterisks indicate identical residues and periods indicate conservative substitutions. The conserved cysteine residues in the extracellular ligand-binding domains are boxed. Transmembrane domain is boxed and shaded. Kinase-insert domain that splits the intracellular kinase domain is underlined. Arrowheads indicate intron positions in the Fugu gene.

1992). Presently only the nucleotide sequence of the CSF1R promoter region upstream of the placental cell transcription initiation site is available and the complete sequence of the $26-\mathrm{kb}$ intron in the $5^{\prime}$ untranslated region is yet to be determined. To identify conserved regulatory elements in the placental cell-promoter region, we compared the promoter sequence of CSF1R (462 $\mathrm{bp}$ from the polyadenylation signal of the PDGFR $\beta$ gene to the transcription initiation site of CSF1R) with the corresponding sequence from the Fugu PDGFR $\beta-C S F 1 R$ loci (500 bp starting from the polyadenylation site of the PDGFR $\beta$ gene). The pairwise comparison made by DotPlot analysis in DNASTAR revealed that three stretches of short nucleotide sequences, TGKGTTCCGGC, CTCCACWGA and ATCAKCTGGGACACC ( $\mathrm{K}=\mathrm{T}$ in Fugu and $\mathrm{G}$ in human; $\mathrm{W}=\mathrm{T}$ in Fugu and $\mathrm{A}$ in human) are conserved in the same order. A nine-nucleotide sequence, CAGATTCCA, is found in both Fugu and human loci at 88 and 438 bases downstream of the polyadenylation signals of the respective PDGFR $\beta$ genes. It is possible that these sequences have some functional significance. A comparison of the $3^{\prime}$ untranslated regions of the Fugu and human PDGFR $\beta$ genes, which are adjacent to the CSF1R promoter region, showed that two short sequences, CTCTGAGCC and TTTATCAC, are conserved completely. The functional significance of these sequences is not known at present. In view of the close proximity of the PDGFR $\beta$ and CSF1R genes, a role for these conserved sequences in the regulation of either or both of these genes cannot be ruled out.

The presence of genes for the PDGF and CSF1 receptors in Fugu indicates that these kinase receptors and their ligands had evolved fully in the common ancestors of teleosts and mammals. The conserved genomic organization, similar primary structure of protein sequences, and the close physical linkage of the Fugu PDGFR $\beta$ and CSF1R genes strongly support the hypothesis that these two genes arose from a common ancestor through gene duplication. Mapping and sequence analysis of the corresponding locus from the most primitive vertebrates such as cyclostomes should help in tracing the evolutionary origin of these genes.

In this paper we have shown that the close physical linkage between the PDGFR $\beta$ and CSF1R genes has been conserved in Fugu and humans. Random sampling of Fugu genomic cosmid clones has shown that there are a number of other examples of conserved synteny between Fugu and humans (for review, see Elgar et al. 1996). The most striking of these is the relative order of three genes-cFOS, S31iii125, and S20i15-which are spread across $>600 \mathrm{~kb}$ in the human familial Alzheimer disease locus (AD3). The order of these genes is conserved in Fugu and all three are located within a $12.4-\mathrm{kb}$ region (Trower et al. 1996). These data show that the synteny has been conserved between Fugu and 


\section{HOW ET AL.}

humans on short stretches of chromosomes. Therefore Fugu is a model genome of choice for characterizing vertebrate genes rapidly with considerably lower sequencing effort compared with other vertebrate genomes.

\section{METHODS}

\section{Isolation of Bacteriophage Clones}

To isolate various receptor tyrosine kinase-genes from Fugu, we designed several pairs of degenerate PCR primers based on the consensus sequences flanking the catalytic domains of mammalian receptor tyrosine kinases. PCR was carried out in a $60-\mu 1$ reaction mix containing $0.2 \mathrm{~mm}$ $\mathrm{dNTP}, 1 \mu \mathrm{M}$ each of forward and reverse primers, 3 units of Taq polymerase and $60 \mathrm{ng}$ of $F u g u$ genomic DNA. DNA was initially denatured at $95^{\circ} \mathrm{C}$ for $2 \mathrm{~min}$, then amplified in 35 cycles of $95^{\circ} \mathrm{C}$ for $30 \mathrm{sec}, 50^{\circ} \mathrm{C}$ for $30 \mathrm{sec}$, and $72^{\circ} \mathrm{C}$ for 1 min, followed by a general extension at $72^{\circ} \mathrm{C}$ for $5 \mathrm{~min}$, in a Perkin Elmer 480 DNA Thermal Cycler. PCR products were end-filled using Klenow Polymerase and subcloned into EcoRI-cut pBluescript plasmid and sequenced. The sequences were searched for homology using the BLASTN program against the protein data bases maintained at the National Center for Biotechnology Information (NCBI). One of the cloned PCR products, TM19, which was amplified using the primers TG(CT)AT(ACT)CA(CT)(AC)G(ACGT)GA(CT)GT and CC(AG)TA(AG)CT CCA(ACGT)AC(GA)TC corresponding to residues CIHRDV and DVWSYG of the mammalian kinases, showed very high homology with mammalian PDGFR $\beta$. This clone was used to probe a Fugu testis genomic library cloned in $\lambda 2001$. The probe was labeled by PCR using $\left[\alpha^{-32} \mathrm{P}\right]$ in the reaction mix. Hybridizing plaques were purified to homogeneity by two more rounds of screening.

\section{Nucleotide Sequence Analysis}

Selected positive phages were subcloned and sequenced either after "exo-deletion" by using the Erase-a-Base system supplied by Promega (Madison, WI), or by a combination of "shot-gun" and primer walking methods. The shot-gun technique involved generating sheared random sublcones in the size range of 400 to $1 \mathrm{~kb}$ and sequencing up to a three-fold redundancy. The sequences were assembled into contigs by using DNASTAR. Gaps in the contigs were closed by directed sequencing using custom oligonucleotide primers. DNA sequencing was done by the radioactive dideoxy chain termination method (Sanger et al. 1977). Multiple sequence alignment was done by using Clustal W (Thompson et al. 1994).

\section{ACKNOWLEDGMENTS}

We thank Dr. Greg Elgar for the Fugu genomic library.

The publication costs of this article were defrayed in part by payment of page charges. This article must therefore be hereby marked "advertisement" in accordance with 18 USC section 1734 solely to indicate this fact.

\section{REFERENCES}

Baxendale, S., S. Abdulla, G. Elgar, D. Buck, M. Berks, G. Micklem, R. Durbin, G. Bates, S. Brenner, S. Beck, and H. Lehrach. 1995. Comparative sequence analysis of the human and pufferfish Huntington's disease genes. Nature Genet. 10: 67-76.

Brenner, S. and L.M. Corrochano. 1996. Translocation events in the evolution of aminoacyl-tRNA synthetases. Proc. Natl. Acad. Sci. 93: 8485-8489.

Brenner, S., G. Elgar, R. Sandford, A. Macrae, B. Venkatesh, and S. Aparicio. 1993. Characterization of the pufferfish (Fugu) genome as a compact model vertebrate genome. Nature 366: 265-268.

Claesson-Welsh, L., A. Eriksson, A. Morén, L. Severinsson, B. Ek, A. Östman, C. Betsholtz, and C-H. Heldin. 1988. cDNA Cloning and expression of a human platelet-derived growth factor (PDGF) receptor specific for B-chain-containing PDGF molecules. Mol. Cell. Biol. 8: $3476-3486$

Coussens, L., C. Van Beveren, D. Smith, E. Chen, R.L. Mitchell, C.M. Isacke, I.M. Verma, and A. Ullrich. 1986. Structural alteration of viral homologue of receptor proto-oncogene fms at carboxyl terminus. Nature 320: $277-280$.

Eccles, M.R. 1991. Genes encoding the platelet-derived growth factor (PDGF) receptor and colony-stimulating factor 1 (CSF-1) receptor are physically associated in mice as in humans. Gene 108: 285-288.

Elgar, G., F. Rattray, J. Greystrong, and S. Brenner. 1995. Genomic structure and nucleotide sequence of the p55 gene of the pufferfish Fugu rubripes. Genomics 27: $442-446$.

Elgar, G., R. Sandford, S. Aparicio, A. Macrae, B. Venkatesh, and S. Brenner. 1996. Small is beautiful: Comparative genomics with the pufferfish (Fugu rubripes). Trends Genet. 12: 145-150.

Hampe, A., B-M. Shamoon, M. Gobet, C.J. Sherr, and F. Galibert. 1989. Nucleotide sequence and structural organization of the human fms proto-oncogene. Oncogene Res. 4: 9-17.

Maheshwar, M.M., R. Sandford, M. Nellist, J.P. Cheadle, B. Sgotto, M. Vaudin, and J.R. Sampson. 1996. Comparative analysis and genomic structure of the tuberous sclerosis 2 (TSC2) gene in human and pufferfish. Hum. Mol. Genet. 5: 131-137.

Mason, R.J., D.J. Stevens, L. Luzzatto, S. Brenner, and S. Aparicio. 1995. Genomic structure and sequence of the Fugu rubripes glucose-6-phosphate dehydrogenase gene (G6PD). Genomics 26: 587-591.

Reedijk, M., X. Liu, P. Van der Geer, K. Letwin, M.D. Waterfield, T. Hunter, and T. Pawson. 1992. Tyr721 regulates specific binding of the CSF-1 receptor kinase 
insert to PI 3'-kinase SH2 domains: A model for SH2-mediated receptor-target interactions. EMBO J. 11: $1365-1372$.

Roberts, W.M., A.T. Look, M.F. Roussel, and C.J. Sherr. 1988. Tandem linkage of human CSF-1 receptor (c-fms) and PDGF receptor genes. Cell 55: 655-661.

Roberts, W.M., L.H. Shapiro, R.A. Ashmun, and A.T. Look. 1992. Transcription of the human colony-stimulating factor-1 receptor gene is regulated by separate tissue-specific promoters. Blood 79: 586-593.

Sanger, F., S. Nicklen, and A.R. Coulson. 1977.

DNA-sequencing with chain-termination inhibitors. Proc. Natl. Acad. Sci. 74: 5463-5467.

Thompson, J.D., D.G. Higgins, and T.J. Gibson. 1994. CLUSTAL W: Improving the sensitivity of progressive multiple sequence alignment through sequence weighting, positions-specific gap penalties and weight matrix choice. Nucleic Acids. Res. 22: 4673-4680.

Trower, M.K, S.M. Orton, I.J. Purvis, P. Sanseau, J. Riley, C. Christodoulou, D. Burt, C.G. See, G. Elgar, R. Sherrington, E.I. Rogaev, P. George-Hyslop, S. Brenner, and C.W. Dykes. 1996. Conservation of synteny between the genome of the pufferfish (Fugu rubripes) and the region on human chromosome $14(14 \mathrm{q} 24.3)$ associated with familial Alzheimer disease (AD3 locus). Proc. Natl. Acad. Sci. 93: 1366-1369.

Venkatesh, B., B.H. Tay, G. Elgar, and S. Brenner. 1996. Isolation, characterization and evolution of nine pufferfish (Fugu rubripes) actin genes. J. Mol. Biol. 259: $655-665$.

Visader, J. and I.M. Verma. 1989. Differential transcription of exon 1 of the human c-fms gene in placental trophoblasts and monocytes. Mol. Cell. Biol. 9: $1336-1341$.

Van der Geer, P. and T. Hunter. 1993. Mutation of Try697, a GRB2-binding site, and Tyr721, a PI 3-kinase binding site, abrogates signal transduction by the murine CSF-1 receptor expressed in Rat-2-fibroblasts. EMBO J. 12: 5161-72.

Yarden, Y. and A. Ullrich. 1988. Growth factor receptor tyrosine kinases. Annu. Rev. Biochem. 54: 443-478.

Received August 14, 1996; accepted in revised form September 18, 1996. 


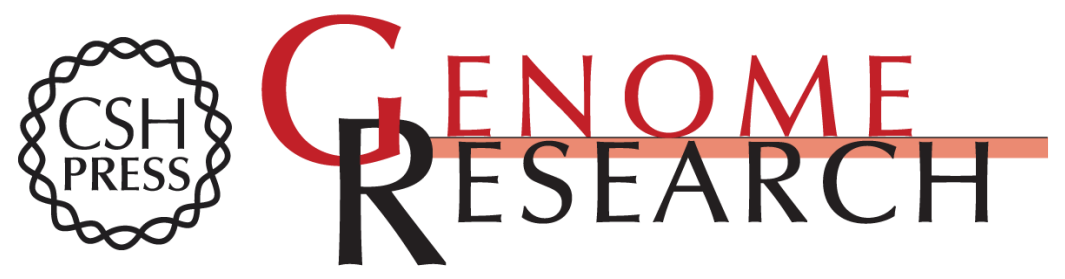

\section{Conserved linkage between the puffer fish (Fugu rubripes) and human genes for platelet-derived growth factor receptor and macrophage colony-stimulating factor receptor.}

G F How, B Venkatesh and S Brenner

Genome Res. 1996 6: 1185-1191

Access the most recent version at doi:10.1101/gr.6.12.1185

References This article cites 21 articles, 6 of which can be accessed free at: http://genome.cshlp.org/content/6/12/1185.full.html\#ref-list-1

License

Email Alerting

Receive free email alerts when new articles cite this article - sign up in the box at the Service top right corner of the article or click here.

\section{Affordable, Accurate Sequencing.}

To subscribe to Genome Research go to:

https://genome.cshlp.org/subscriptions 